This item was submitted to Loughborough's Research Repository by the author.

Items in Figshare are protected by copyright, with all rights reserved, unless otherwise indicated.

\title{
Experimental study on laminar flame characteristics of methane-PRF95 dual fuel under lean burn conditions
}

PLEASE CITE THE PUBLISHED VERSION

http://dx.doi.org/10.1016/j.fuel.2016.07.065

\section{PUBLISHER}

(c) Elsevier Ltd.

\section{VERSION}

AM (Accepted Manuscript)

\section{PUBLISHER STATEMENT}

This work is made available according to the conditions of the Creative Commons Attribution-NonCommercialNoDerivatives 4.0 International (CC BY-NC-ND 4.0) licence. Full details of this licence are available at: https://creativecommons.org/licenses/by-nc-nd/4.0/

\section{LICENCE}

CC BY-NC-ND 4.0

\section{REPOSITORY RECORD}

Wei, Haiqiao, Dongzhi Gao, Lei Zhou, Sotiris Petrakides, Rui Chen, Dengquan Feng, and Jiaying Pan. 2016. "Experimental Study on Laminar Flame Characteristics of Methane-prf95 Dual Fuel Under Lean Burn Conditions". figshare. https://hdl.handle.net/2134/22337. 
3

4 5

6

\section{Experimental study on laminar flame characteristics of}

\section{methane-PRF95 dual fuel under lean burn conditions}

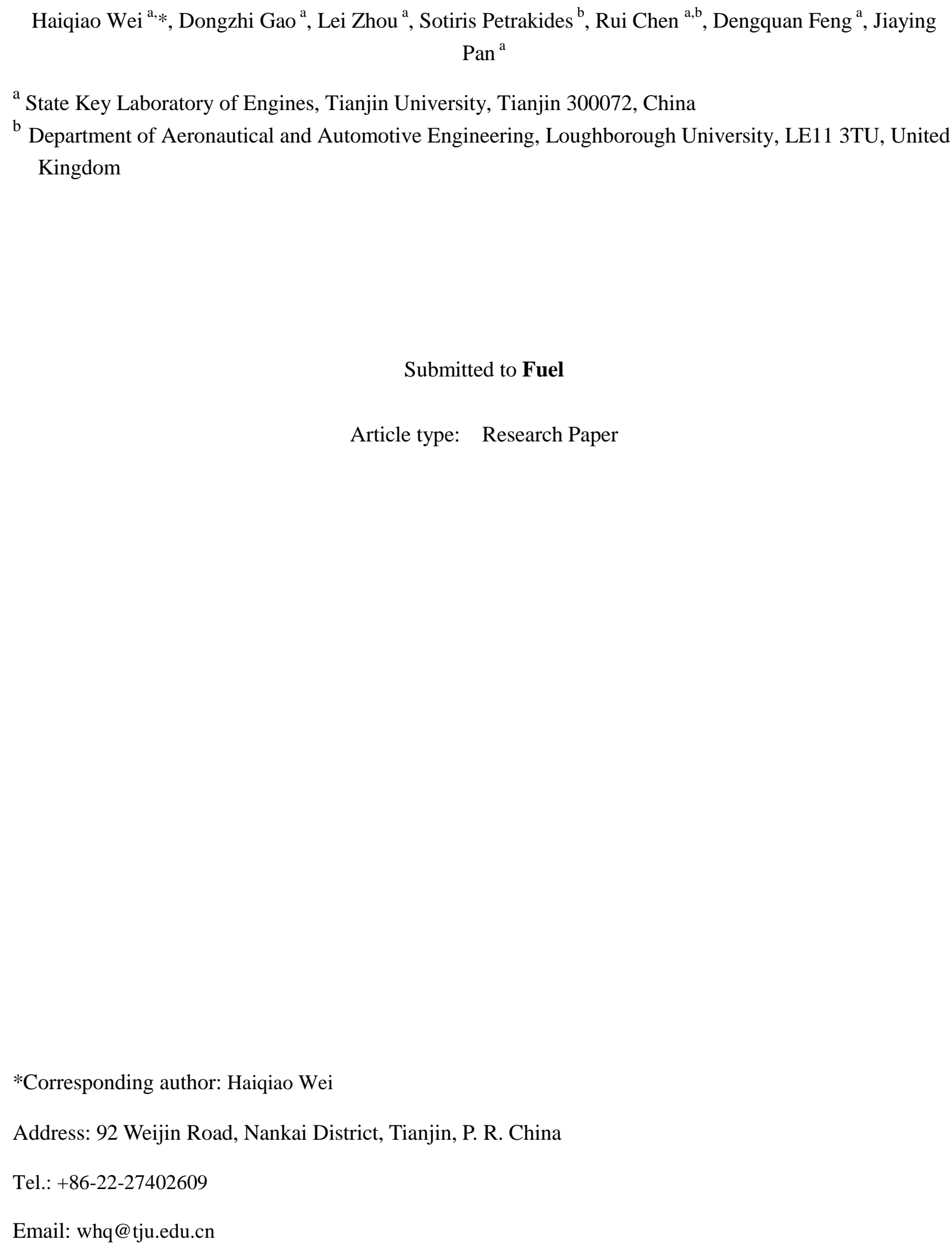




\section{Abstract}

The effects of methane addition to PRF95 (primary reference fuel with 95\% volume of iso-octane and $5 \%$ volume of n-heptane) on the fundamental combustion parameters are experimentally investigated in a cylindrical combustion vessel using classical schlieren technique. In this study, methane is added with three energy fractions of 25\%, 50\% and 75\% to PRF95. The laminar flame propagation, Markstein length and flame instability of dual fuels under different initial pressures and with different equivalence ratios, especially under lean burn condition, are well studied. Spherical flames are experimentally investigated at the initial temperature of $373 \mathrm{~K}$ and under the pressures of $2.5 \mathrm{bar}, 5$ bar and 10 bar. The equivalence ratios vary with $0.8,1.0$ and 1.2. The stretched flame speeds are determined by outwardly spherical flame method. The results show that at low initial pressures, the addition of methane to PRF95 increases the stretched flame speeds with lean equivalence ratios while decreases it in rich region. Laminar flame of methane-PRF95 mixtures burn faster than those of pure methane and PRF95 with equivalence ratio of 0.8 over the whole range of the initial pressures investigated, and this trend is more obvious at low pressure. Comparing the data of 25\% methane dual fuel (DF25) with that of base fuels with the equivalence ratio of 0.8 and under the initial pressure of 2.5 bar, it can be seen that the flame speed of DF25 is $57 \%$ faster than that of methane and 22\% faster than that of PRF95. These results provide important theoretical references to lean burn SI engine with methane-gasoline dual fuels under lean burn conditions.

Keywords: Methane-PRF95; Laminar flame speed; Lean burn; Flame instability

\section{Introduction}

Lean combustion is one of the most developed technologies in spark ignition (SI) engines. Compared with stoichiometric operation, lean combustion in SI engines reduces $\mathrm{NO}_{\mathrm{x}}$ emissions as well as fuel consumption. In addition, lean combustion can improve engine part load characteristics and reduce the trend of engine knock in downsized SI engines. However, in lean burn gasoline engines, the ignition delay time might become long and the flame propagation might become slow, resulting in the reduction of combustion efficiency. On the other hand, lean combustion is less stable, and great cycle-to-cycle variation occurs during flame initiation and development, which will lead to poor drivability [1-3]. Methane, as one of the most promising alternative fuels for internal combustion engines, is abundant all over the world and can be regenerated as a biomass fuel. It has been used in small passenger cars as an alternative fuel of gasoline, which features many advantages, such as high knocking resistance and low $\mathrm{CO}_{2}$ emissions. 
However, its slow flame speed and low energy density are the major obstacles for use in actual combustion application. In recent years, methane-gasoline dual fuel has been considered as a potential choice as an alternative fuel for spark ignition (SI) engines, especially for downsized engines with turbocharger that can use the advantages of both the fuels [4-6]. As emphasized in the literature of experimental studies [7-9], methane-gasoline dual fuel has the potential to improve mixture combustion, leading to an enhanced initial establishment of burning speed, even compared to that of gasoline. Thus the application of methane-gasoline dual fuel (DF) in lean burn SI engine can solve the following issues at the same time: broadening combustion limit and enhancing flame speed, improving emission characteristics and cycle-to-cycle variation, as well as engine part load characteristics.

Recently, some practice engine experiments using methane-gasoline, as well as its surrogate fuel, n-heptane and iso-octane have been conducted by Gou et al. [4], Pipitone et al. [5] and Delpech et al.[6]. They reported power or emission improvements in different level for dual fuels at their own conditions, but there hasn't been unified conclusion. It is because that actual engine test condition is complex and varies among researchers. Therefore, this study shows the fundamental laminar flame propagation characteristics in constant volume combustion bomb (CVCB) to investigate the effect by single parameter, such as initial pressure and equivalence ratio. In addition, the previous researchers are still very limited in the performance of DF in SI engine.

For combustion fundamental research, Baloo et al. [9] investigated the laminar burning speed, flame instability and burning flux of iso-octane/methane blend using schlieren photography. The results showed that the addition of methane to iso-octane increases the unstretched propagation speed in lean region but decreases the unstretched propagation speed in rich region. For the fundamental investigation of laminar flame, most efforts have been confined to hydrogen addition to increase methane (CNG) or iso-octane flame speed. They found that the addition of hydrogen promotes the ignitable range, the burning speed the flame stability. The laminar burning characteristics of methane-PRF95/gasoline blended fuel has not been well understood, which is a physiochemical property that influences the emissions and performance of the combustion process in many combustion devices. On the other hand, the fundamental research can be used to develop models for numerical simulation of combustion. Thus, the fundamental investigation of methane-gasoline dual fuel is necessary, especially with low equivalence ratios.

The objective of this study is to experimentally investigate the combustion characteristics of dual fuel 
consisting of methane with three energy ratios compared with base fuels, such as laminar flame propagation, Markstein length and flame instability, under different initial pressures and with different equivalence ratios, especially under lean burn condition. The present work provides a new insight into the laminar flame propagation of dual fuel. The tests were performed under the initial pressures of 2.5 bar, 5 bar and 10 bar, with an initial temperature of $373 \mathrm{~K}$. The equivalence ratios vary with $0.8,1.0$ and 1.2. Each point of the tests was repeated at least three times to ensue reproducibility. As gasoline is a mixture of many species and would be too complex for detailed chemical reaction mechanism analysis, PRF95 was used in this study as a representative component of gasoline [10,11]. The present study is very helpful to improve the chemistry mechanism of DF for numerical combustion simulation and to understand the performance of DF in actual SI engine.

The paper is organized as follows: the experimental setup and conditions are briefly discussed in Section 2; Section 3 illustrates the laminar combustion theory; the results and discussion are presented in Section 4, involving the analysis of flame morphology, stretched flame speed, Markstein length and flame instability; finally, major conclusions from this work are drawn in the last section.

\section{Experiment}

\subsection{Experimental setup}

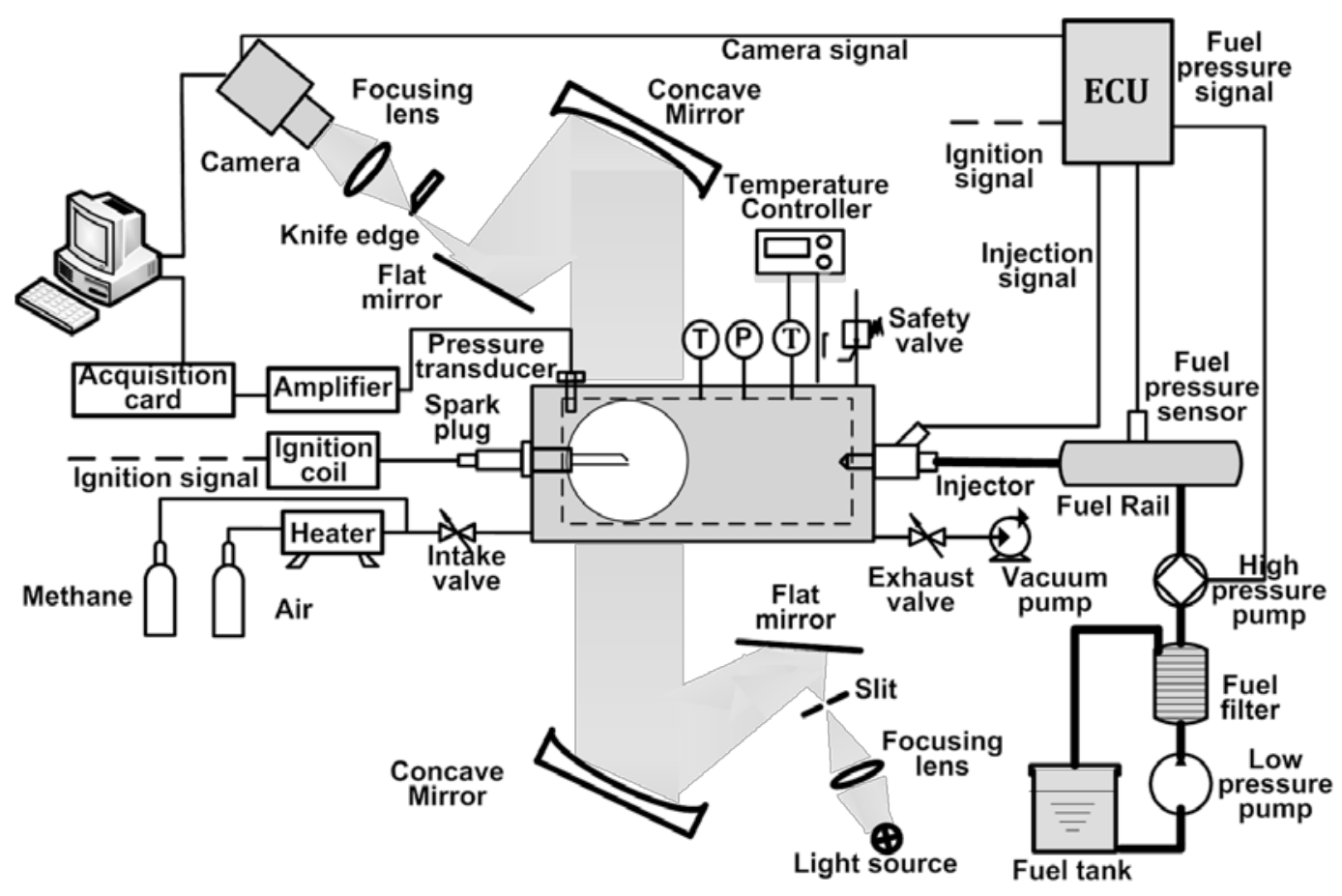

Fig. 1. Schematic diagram of the experimental setup.

A $100 \mathrm{~mm}$ inner diameter cylindrical combustion vessel with a volume of $2.32 \mathrm{~L}$ was employed for 

preheated by a set of electrical heating elements totaling 2,000 W. The interior air temperature was controlled within $3 \mathrm{~K}$ using a closed-loop feedback controller set to 373K. The mixture was ignited using a slightly modified standard ignition plug with extended electrodes. The ignition system generated a spark with duration of $0.7 \mathrm{~ms}$ and the timing was synchronized with the high-speed camera which has the speed of 6,000 frames per second using a resolution of $512 * 512$ pixels. More details of the experimental specifications can be found in reference [12].

\subsection{Experimental procedure}

In the present work, dual fuel of methane and PRF95 (95\% volume of iso-octane and 5\% volume of n-heptane) is studied under pressures of 2.5 bar, 5 bar and 10 bar, at initial temperature of $373 \mathrm{~K}$ and with equivalence ratios of $0.8,1.0$ and 1.2. Mixtures were prepared in the vessel, which was initially evacuated. The required quantity of the fuel PRF95 was injected in liquid state with a calibrated spray injector, which was situated vertically on the right wall of the chamber. The fuel methane was from pressurized cylinders. In this study, the dual fuel blend consisted of methane with three energy ratios of $25 \%, 50 \%$ and $75 \%$, marked as DF25, DF50 and DF75 respectively. For the liquid fuel, PRF95 was used. High purity methane was used as the gaseous fuel. The dual fuel blends consist of methane and PRF95 in three different energy ratios (25\%, 50\%, 75\%). A blend with 25\% of its energy contributing from methane as defined in Equation (1) was labelled as DF25, with 50\% DF50, and for 75\% DF75.

$$
D F_{\text {Ratio }}=\frac{M_{C H 4} \times L H V_{C H 4}}{M_{P R F 95} \times L H V_{P R F 95}+M_{C H 4} \times L H V_{C H 4}}
$$

Where $M$ represents the number of mole of fuel and $L H V$ indicates low heating valve.

Dry air (80\% $\mathrm{N}_{2}$ and $20 \% \mathrm{O}_{2}$ ) was added to all the fuels from a cylinder, in order to let the mixture achieve the pressures of 2.5 bar, 5 bar, 10 bar as required, as well as required equivalence ratio at ignition, for the tests presented here. Prior ignition, the fuel and the air mixture were initially premixed for 5 minutes to realize homogeneous mixture under the target condition of initial temperature, 373K, which was selected to guarantee iso-octane and n-heptane were completely vaporized prior combustion, under all the pressures and at the equivalence ratios. Finally, the spark igniter, pressure recorder and high-speed digital video camera were triggered simultaneously by synchronization. For each of the testing points, three measurements were carried out to check repeatability. The experimental conditions are summarized, as 
146 in the different DF mixtures are presented in Table 2. In this study, the relative errors for the temperature

147 and initial pressure are $1 \%$ and $0.5 \%$, respectively. The relative error of measured values (flame radius, 148 stretched flame speed) all have their maximum value of $3 \%$.

Table 1 Experimental conditions.

\begin{tabular}{ll}
\hline Parameters & Value \\
\hline Combustion chamber volume/V & $2.32 \mathrm{~L}$ \\
Initial temperature $/ T_{0}$ & $373 \mathrm{~K}$ \\
Initial pressure $/ P_{0}$ & 2.5 bar, 5 bar, 10 bar \\
& CH4, PRF95, DF25, \\
Fuel & DF50, DF75 \\
& $0.8,1.0,1.2$ \\
\hline
\end{tabular}

Table 2 Mole fractions of base fuels in the DF mixture.

\begin{tabular}{ccc}
\hline DF ratio (\%) & $\mathrm{X}_{\mathrm{CH} 4}$ & $\mathrm{X}_{\mathrm{PRF} 95}$ \\
\hline 0 & 0 & 1 \\
25 & 0.68 & 0.32 \\
50 & 0.86 & 0.14 \\
75 & 0.95 & 0.05 \\
100 & 1 & 0 \\
\hline
\end{tabular}

151 


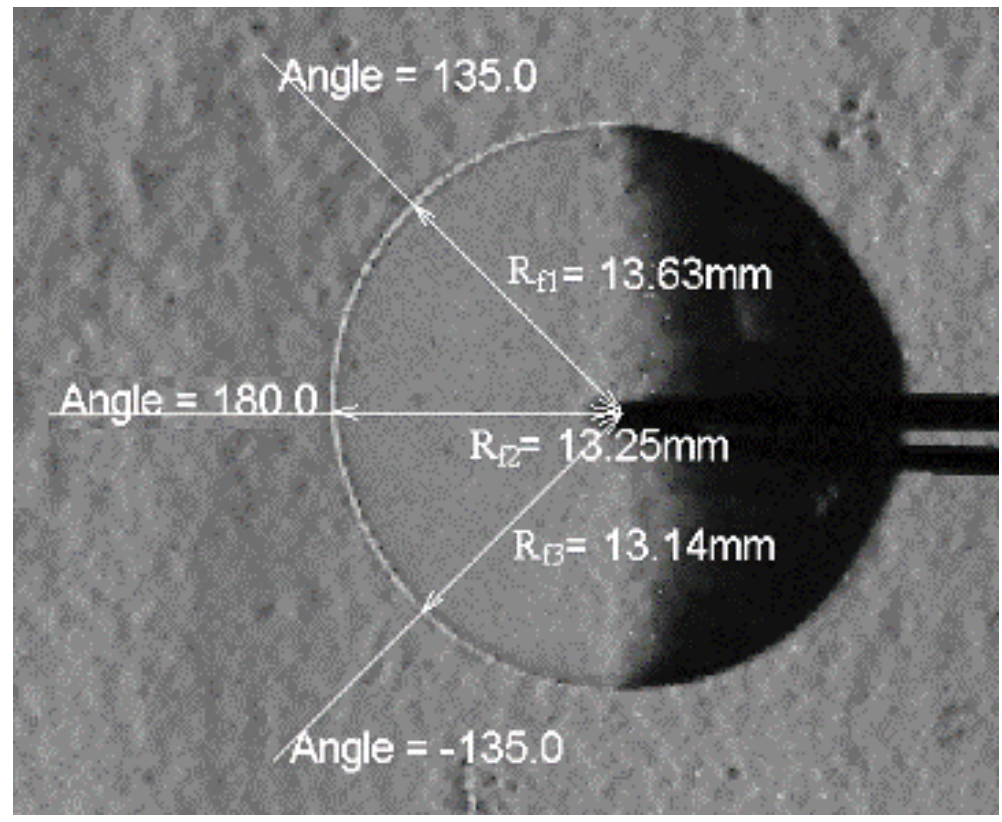

Fig. 2. Detection of temporal flame edge.

Because of the impact of flame quenching from the electrodes, the flame speed along the direction of the electrodes is slow, thus the flame is not perfectly spherical. The flame front on the left side of spherical flame is used to measure the flame radius, as shown in Fig. 2. The averaged value in the three directions $(135,180,-135)$ on the left hemisphere presents the flame radius $r_{u}$. This operation was performed as a semiautomated batch process in PCO Picture Viewer software. Experiments $[5,13]$ suggest that the flame speed is independent from ignition energy when the flame radius is larger than $6 \mathrm{~mm}$. Therefore, this study neglected the data with radius of below $6 \mathrm{~mm}$ in order to avoid the effect of spark-ignition disturbance. As described in reference [14], for cylindrical chambers, data analysis should be restricted to flame radii less than 0.3 times of the wall radius. Therefore, when the flame radius is less than $15 \mathrm{~mm}$ in this study, the pressure increase in chamber is negligible and the effect of cylindrical confinement on the determination of flame speed can be neglected. Thus, only the flame images with radius between $6 \mathrm{~mm}$ and $15 \mathrm{~mm}$ were selected to obtain the flame speed. Besides, meaningful determination of the flame speed precludes the instances exhibiting flame-front cellular structure.

\section{Spherical flame analysis}

For an outwardly propagating spherical flame, the stretched flame speed $S_{n}$ is calculated according to the temporal derivative of the flame radius development $[13,15,16]$ :

$$
S_{n}=\frac{d r_{u}}{d t}
$$


Where $r_{u}$ is flame radius, $t$ is the elapsed time after ignition.

The stretch rate $\alpha$ originates from the strain and the curvature of flame surface, which can be defined as:

$$
\alpha=\frac{d(\ln A)}{d t}=\frac{1}{A} \frac{d A}{d t}
$$

Where A is flame area.

For an outwardly propagating spherical flame, the formula of spherical area is introduced as:

$$
\alpha=\frac{1}{A} \frac{d A}{d t}=\frac{2}{r_{u}} \frac{d r_{u}}{d t}=\frac{2}{r_{u}} S_{n}
$$

The unstretched flame speed $S_{l}$ can be extracted as explained with linear method in references $[17,18]$. The linear equation is shown as:

$$
S_{l}-S_{n}=L_{b} \alpha
$$

Where $L_{b}$ is the Markstein length relative to burned gas, and $\alpha$ is the flame stretch rate. $S_{l}$ is obtained from the linear extrapolation based on the plot of $S_{n}-\alpha$ as the intercept value of $S_{b}$ at $\alpha=0$. The Markstein length $L_{b}$ of the burned gas is the negative value of the gradient from the best linear regression of the flame speed against the stretch rate curve. It's noted that linear method is used in the presrnt study due to the little difference in comparison of linear and nonlinear methodologies with lean equivalence ratios, as shown in reference[19].

Finally, the laminar burning speed $u_{l}$ can be calculated with the following equation[13,16],

$$
u_{l}=\frac{S_{l}}{\sigma}=\frac{\rho_{b}}{\rho_{u}} S_{l}
$$

$\rho_{u}$ and $\rho_{b}$ are the densities of the unburned and burned gases, respectively. And $\sigma$ is the expansion factor which is the ratio of the density of the unburned gas to burned gas. The density ratio is calculated with CHEMKIN software using simplified chemical kinetic mechanism (171 specifies and 861 reactions) by Luong et al. [20]. The laminar burning speed $u_{l}$ can be derived by dividing the reported values of $S_{l}$ with appropriate expansion factors. In this study, under each tested condition, the computed expansion factors are presented in Table 2.

Table 3 Expansion factor of different fuels at the initial temperature of 373K.

\begin{tabular}{lllllll}
\hline$\Phi$ & $\mathrm{P}_{0} /$ bar & PRF95 & DF25 & DF50 & DF75 & Methane \\
\hline 0.8 & 2.5 & 5.8099 & 5.6609 & 5.5247 & 5.4347 & 5.2239 \\
\hline
\end{tabular}




\begin{tabular}{llllll}
\hline 5 & 5.8326 & 5.7085 & 5.5710 & 5.4626 & 5.2849 \\
10 & 5.8622 & 5.7200 & 5.5803 & 5.4617 & 5.3130 \\
\hline
\end{tabular}

\section{Results and discussion}

\subsection{System validation}

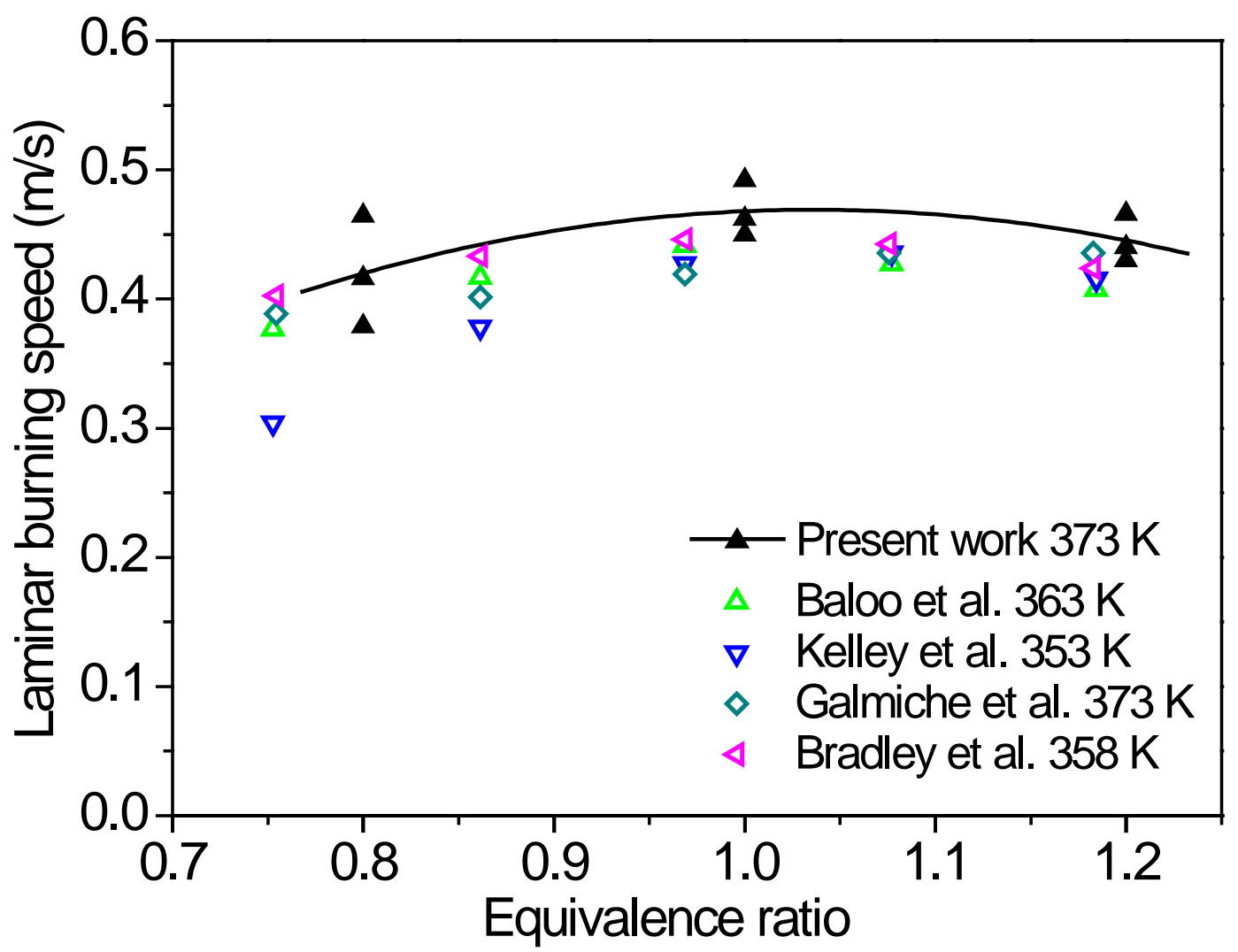

Fig. 3. Comparison of the laminar burning velocities versus equivalence ratios from the current work and other research's results at the pressure of 1 bar.

For the validation of the measured laminar flame speed in this study, we review some relevant literatures $[9,13,21,22]$. There are no experimental data about laminar burning speed of methane-PRF95 blend. Therefore, laminar burning speed of PRF95-air mixtures were measured and compared with the data of iso-octane from previous literatures to validate the current measurement system. Fig. 3 shows the comparison between the present measurement laminar burning speed of PRF95 with the results of Baloo et al. [9], Kelley et al. [21], Galmiche et al. [22] and Bradley et al. [13]. As shown in the figures, the laminar burning speed of PRF95 in the present work is in the same order of the magnitude with the iso-octane versus equivalences ratios in the above literatures. Thus the measured laminar flame speed in the current study is reasonable and correct.

\subsection{Flame morphology}




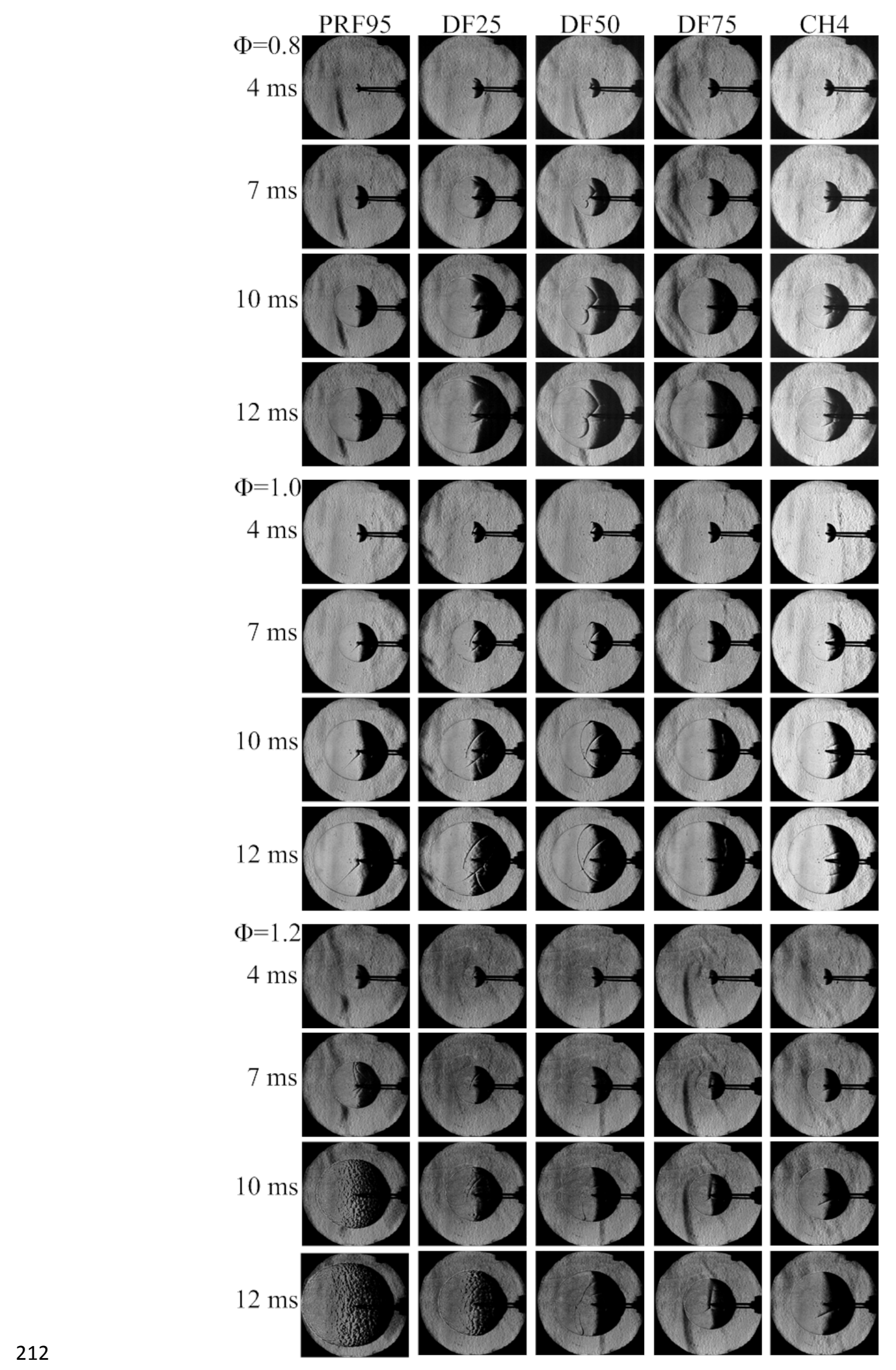

Fig. 4. Chronological schlieren images for different fuels at $2.5 \mathrm{bar}$. 

1.0 and 1.2) at an initial temperature of $373 \mathrm{~K}$ and under initial pressures of 2.5 bar. As shown, the differences in equivalence ratio and methane fraction have significant impact on the development of laminar flame. When the equivalence ratio is 0.8 , the propagation speed of dual fuel is faster than that of the base fuels. With the decrease of methane mixing ratio, the development of laminar flame increases and the flame speed of DF25 is clearly the highest. When the equivalence ratio is 1.0, the differences between the cases of dual fuel and the base fuel is very insignificant. With the equivalence ratios of 0.8 and 1.0, the flame surface remains smooth during flame propagation within the test window of $80 \mathrm{~mm}$. It is noted that although the electrodes might occasionally induce some cracks over the flame front, these cracks do not necessarily develop into cells and affect the overall shape. However, flame speeds of dual fuel are slower than that of the base fuels when the equivalence ratio is 1.2. The flame speed of PRF95 is much faster than that of methane under this condition. The flame becomes wrinkled as the methane mixing ratio decreases.

The cellular structure was observed after 7ms with PRF95 and 10ms with DF25 with equivalence ratio of

is different from our expectation, which is the focus of this paper.
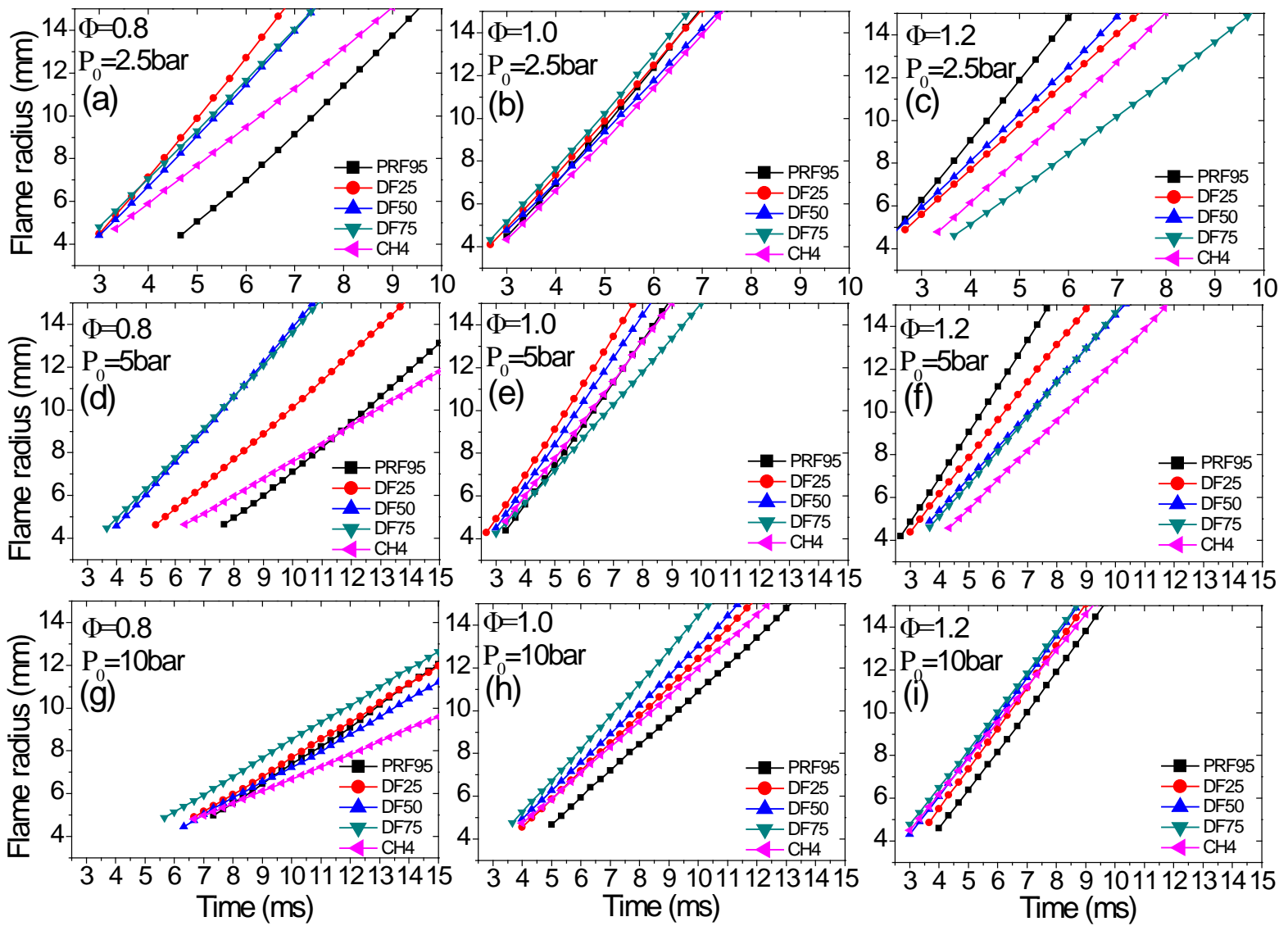
Fig. 5. The relationship of flame radius against time under different initial conditions.

Figure 5 shows the relationship of flame radius versus time with different equivalence ratios of 0.8 ,

232

1.0 and 1.2 and under the initial pressures of 2.5 bar, 5 bar and 10 bar. As can be seen from the figures, with the increase of initial pressure, the slopes of these curves decrease. This indicates that the flame speed decreases. Under stoichiometric conditions, the flame evolution of different fuels is similar, showing that the methane added into stoichiometric ratio mixture has little effect on flame propagation. It is noted that the slopes of dual fuel with lean equivalence ratio (0.8) and under low initial pressure (2.5bar) as shown in Fig. 5a are greater than that of the base fuel. This indicates that dual fuel has certain advantages if used in lean burn SI engine. These are also presented in Fig. 4. Therefore, we focus on the test cases with the equivalence ratio of 0.8 in the following sections.

\subsection{Stretched flame speed, Markstein length}

\subsubsection{The effect of different initial pressures}

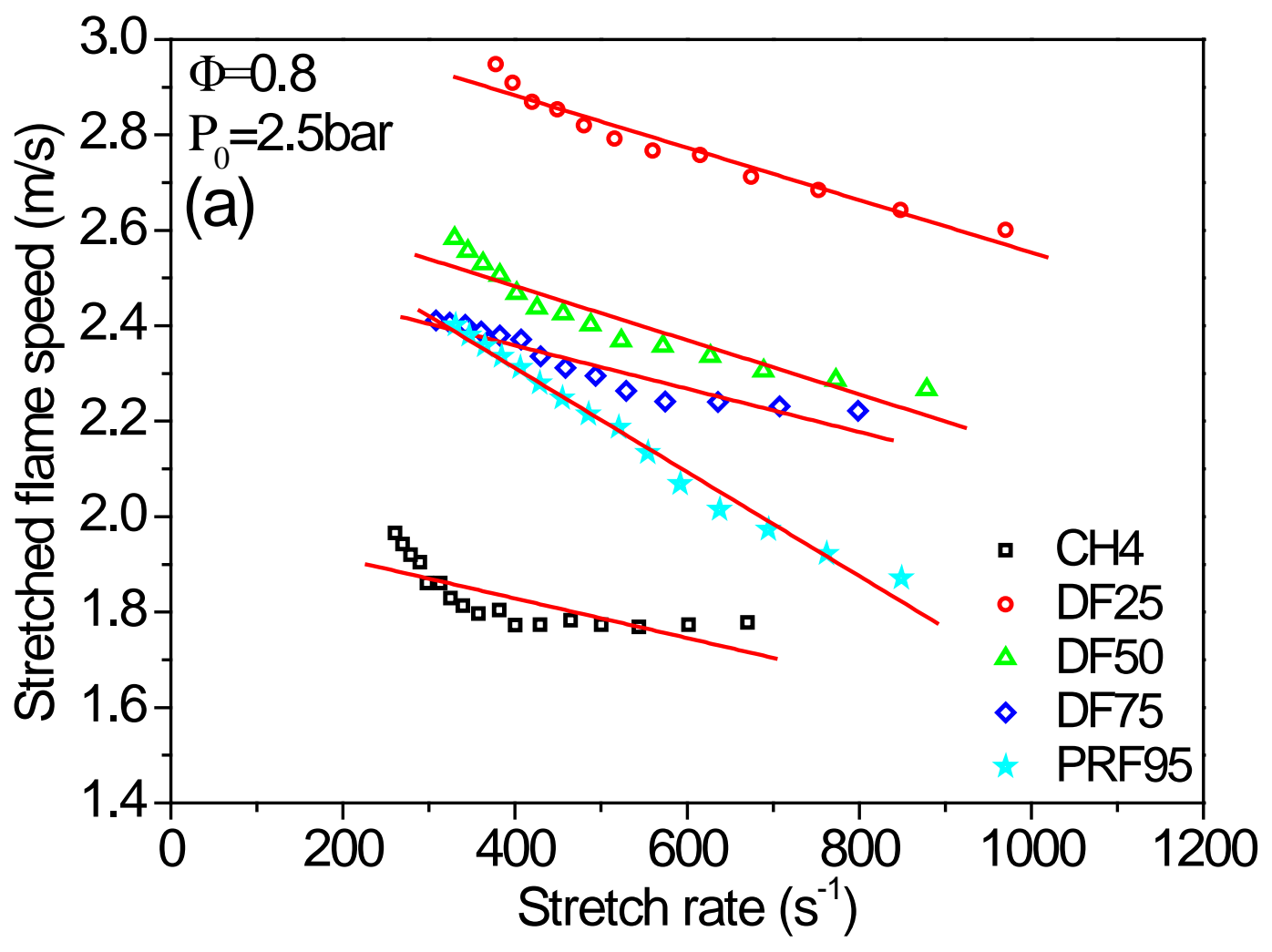



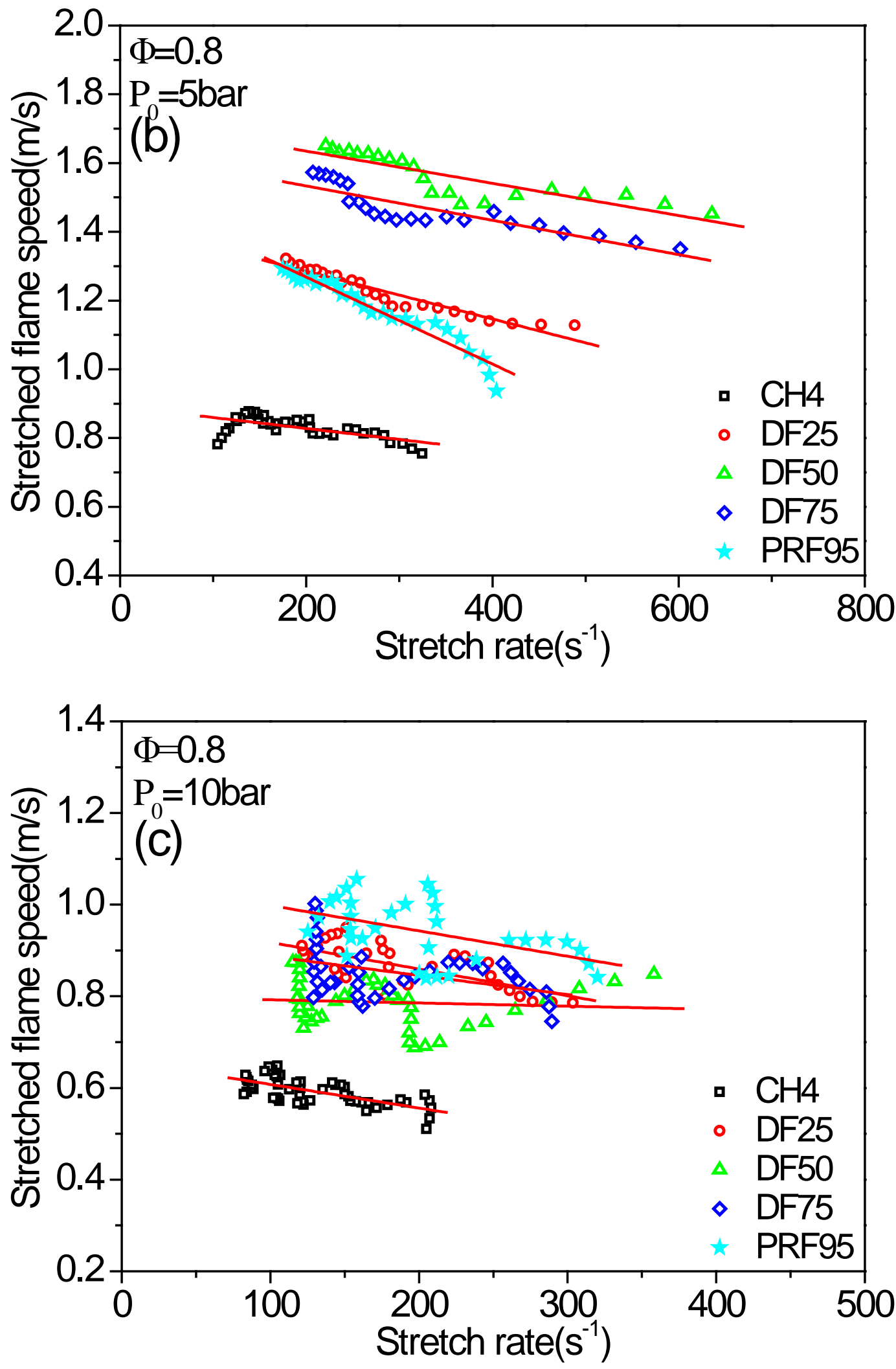

Fig. 6. Stretched flame speed of the test fuels with equivalence ratio of 0.8 under different initial pressures.

Figure 6 shows the measured stretched flame speeds with respect to the stretch rate for lean mixtures under three different initial pressures. Because of the inverse proportionality between the flame stretch rate 
and flame radius as shown in Eq. 2, the flame stretch rate decreases as the radius increases. In general, the stretched flame propagation velocity decreases with the increase of the initial pressure. For a given initial pressure, the stretched flame speed shows a decreasing tendency with increasing stretch rate. Thus, the burned Markstein length, the negative value of the slope from the best linear regression of flame propagation versus stretch rate curve, is positive. It is similar to the previous work by D. Bradley, et al. [13]. At 2.5 bar, the difference of propagation speed among different fuels is great. The flame speed of dual fuel is faster than that of the base fuel, and decreases with the increase of the blending ratio of methane. DF25 has a maximum flame speed under this condition. This is consistent with the trend described above in Fig. 4. As the initial pressure rises to 5 bar, the flame speed of the base fuel is still lower than that of dual fuel. In this case, DF50, the $50 \%$ mixing ratio of methane, showed the fastest velocity of flame propagation. For the initial pressure of 10 bar, the stretched laminar flame speeds for all the tested fuels are further reduced, and they are more unstable versus stretch rate. The flame speeds of dual fuels are lower slightly than that of PRF95 but faster than $\mathrm{CH}_{4}$, and the difference between them is small. These results suggest that, low proportion of methane fuel blended gasoline can promote the development of laminar flame under the conditions of low pressure and with lean equivalence ratio. This indicates that lean methane dual fuel has advantages if used in lean combustion SI engine. However, under high initial pressures of 10 bar, the response of the flame evolution to the DF ratio is totally different compared to that under the low pressures. 

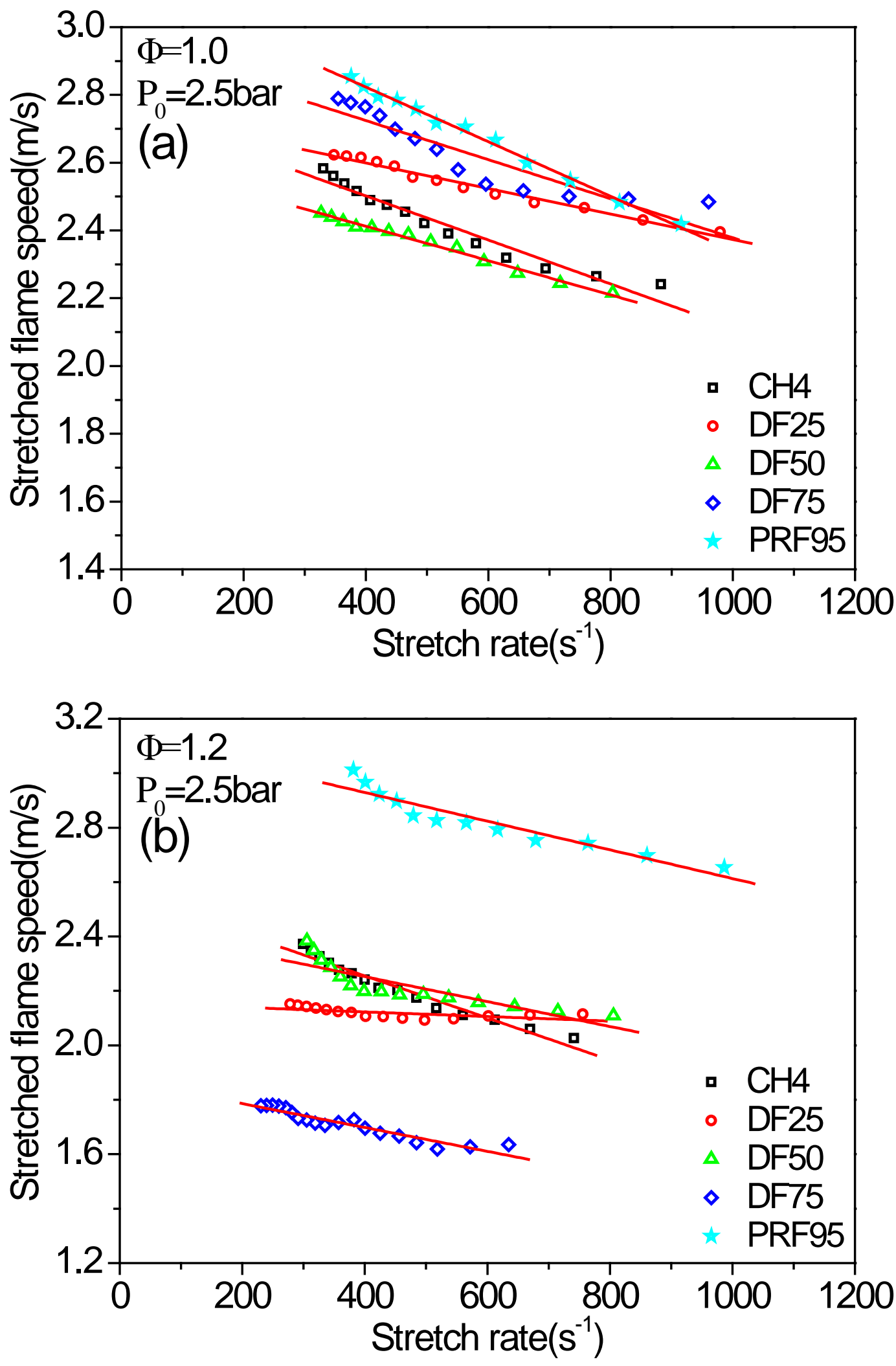

Fig. 7. Stretched flame speed of the test fuels under initial pressure of 2.5 bar with different equivalence 
272 equivalence ratios of 1.0 and 1.2, and the case of equivalence ratio of 0.8 can be found in Fig. 6a above. In 273 general, the flame speed of each fuel has a little difference when the equivalence ratio is 1.0. As the 274 mixture being rich or lean, the difference between the speed of each fuel becomes evident. As shown in Fig.

275 7a, the stretched flame speed of the five test fuels are similar in the range of 2.3 to $2.8 \mathrm{~m} / \mathrm{s}$. PRF95 and 276 DF50 have the fastest and slowest flame speed, respectively. At the rich equivalence ratio of 1.2, PRF95 277 has faster flame speed than other fuels. In other words, the propagation speed of dual fuel does not increase 278 at rich equivalence ratio of 1.2. This is different with the tendency as shown in Fig. 6a.

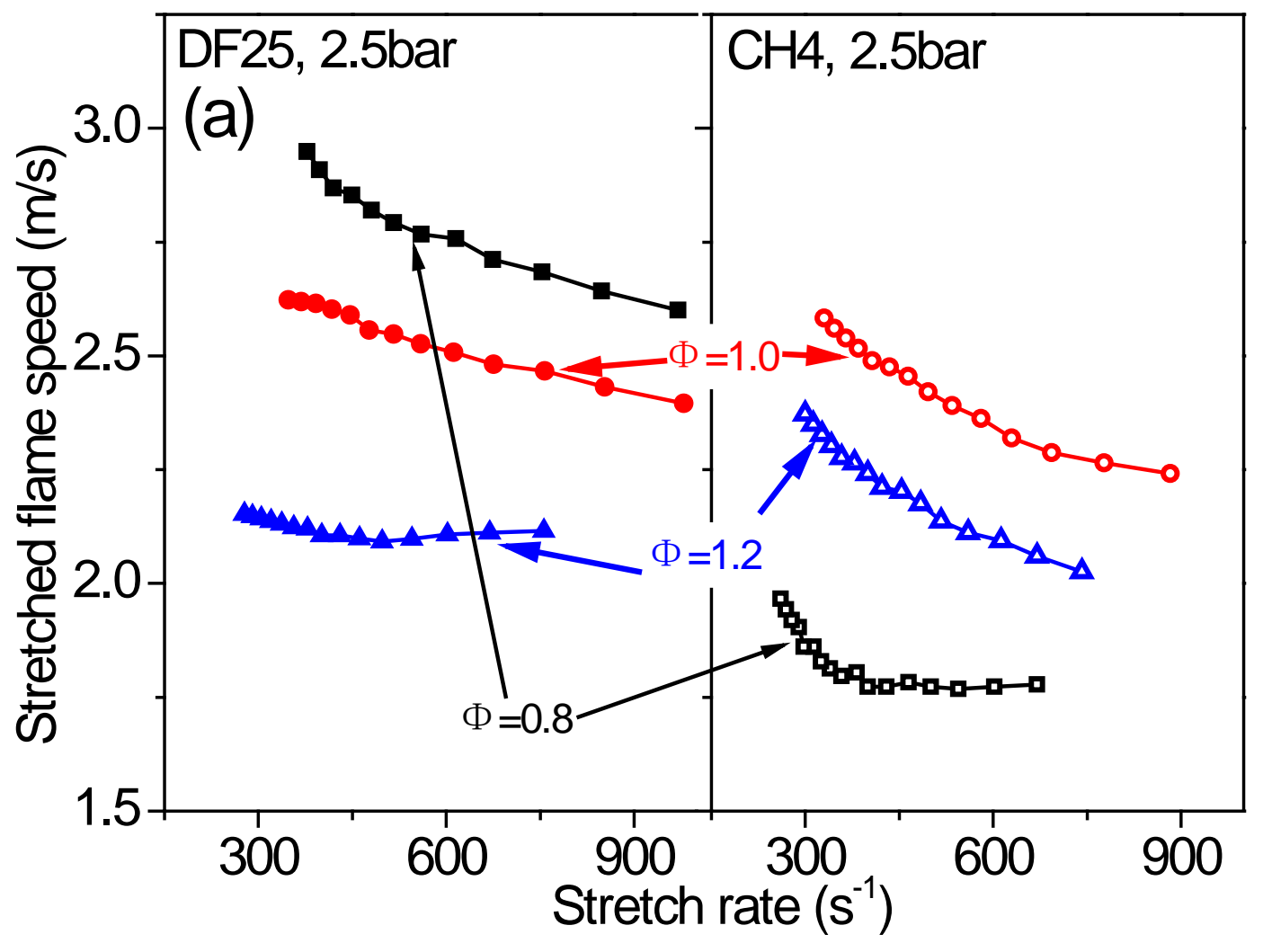




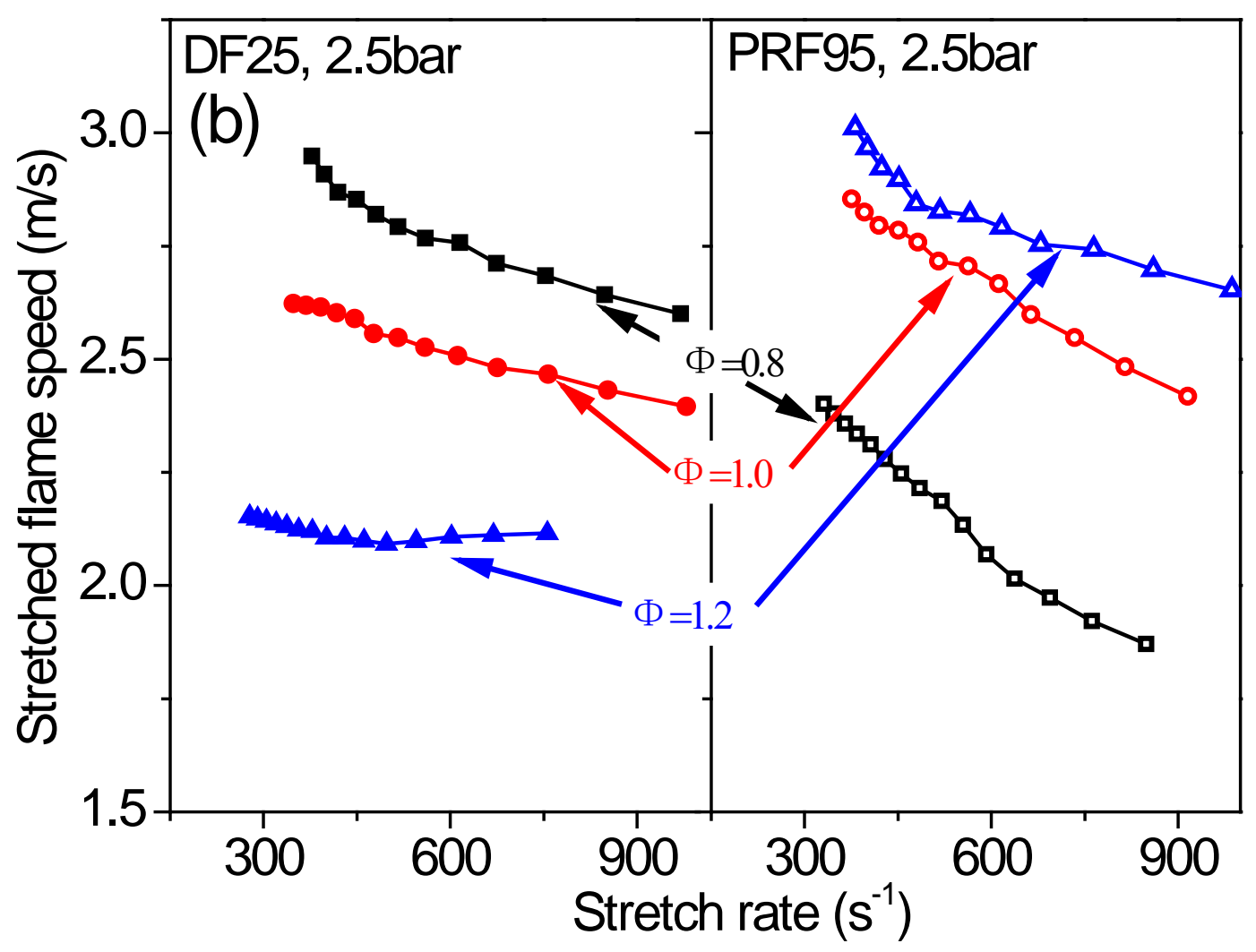

Fig. 8. The comparison between DF25 and the base fuels in stretched flame speed at initial pressure of 2.5 bar.

Stretched flame speeds of methane and PRF95 to DF25 are compared in Fig. 8 with different equivalence ratios under the initial pressure of 2.5bar. The flame speed is plotted against flame stretch rate. It can be seen that the maximum stretched flame speed of methane versus the stretch rate appears at the equivalent ratio of 1.0 and the minimum speed is observed with low equivalent ratio, which is in good agreement with previous study [17]. However, it should be noted that the blended fuel of methane with PRF95 completely changes the evolution of stretched flame versus equivalence ratios, which provides a new insight into the laminar flame propagation of dual fuel. In the meantime, comparing the experimental data of DF25 and methane at equivalence ratio, $\varphi=0.8$, it can be seen that adding methane leads to $57 \%$ increase of stretched flame speed from $1.75 \mathrm{~m} / \mathrm{s}$ to $2.75 \mathrm{~m} / \mathrm{s}$, as shown in Fig. 8a. When $\varphi=1.0$, blending methane has no effect on the flame propagation. For the rich mixture the flame speed of DF25 declines by 7\% compared than that of methane.

In contrast, the stretched flame speed of DF25 and PRF95 with different equivalence ratios are shown in Fig. 8b. The variations of the stretched flame speed of PRF95 with the stretch rate for three different equivalence ratios under 2.5 bar is similar to the reference [13]. From the equivalence ratio of 1.2 to 0.8 , 
the stretched flame speed decreases, which is also different from the evolution of stretched flame speed of methane. However, when $\varphi=0.8$, the flame speed of DF25 is $22 \%$ faster than that of PRF95. As equivalence ratios are 1.0 and 1.2, the flame speed of DF25 is slower than that of PRF95, and there is strengthening tendency with the increase of equivalence ratio. In addition, with the incorporation of methane, the slope of the curve decreases, indicating a flame less sensitive to changes in the stretch rate.

\subsubsection{Markstein length}

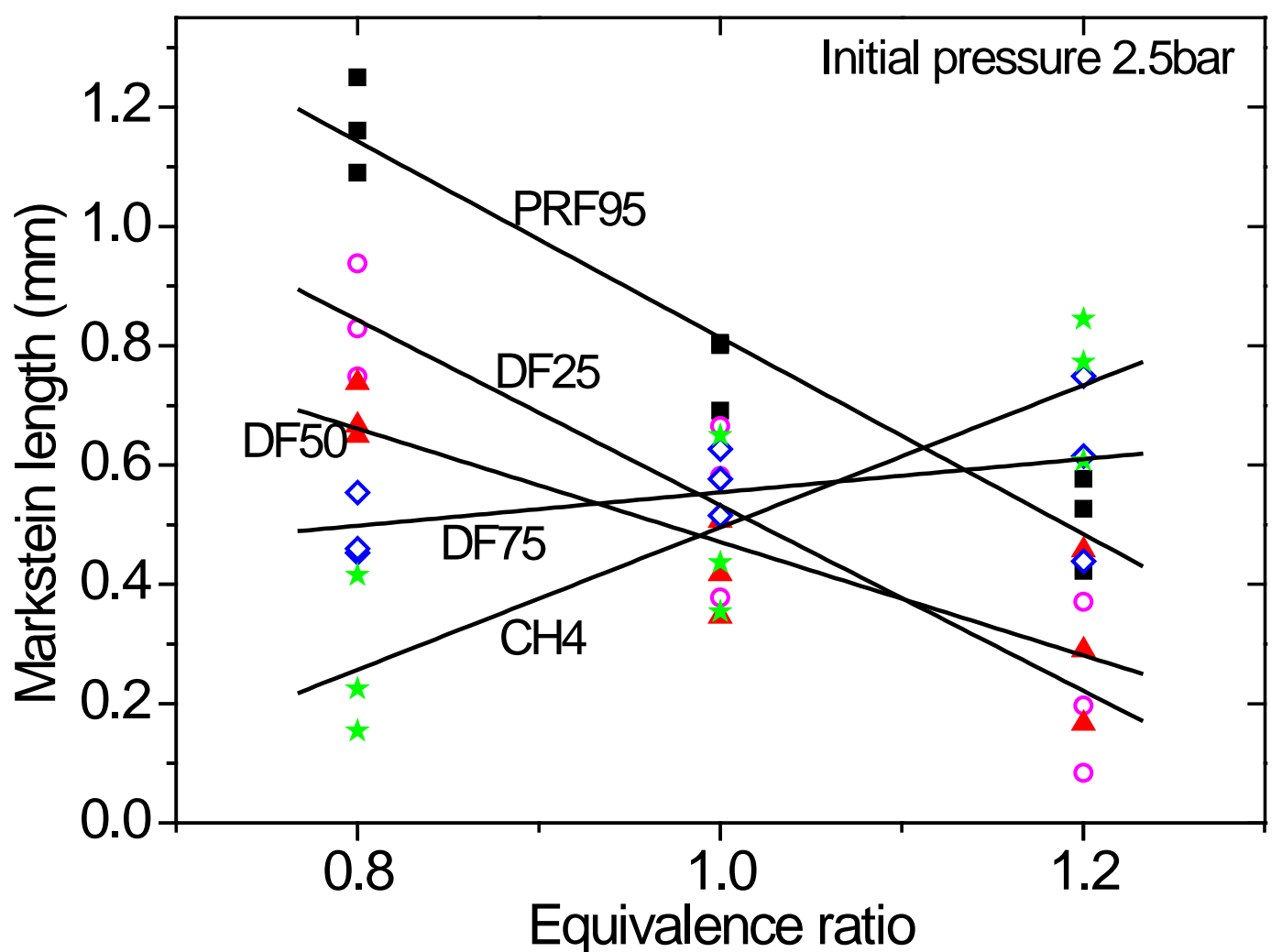

Fig. 9. Burned gas Markstein length versus equivalence ratio linear fits through data.

Figure 9 shows the variation in derived burned gas Markstein length $L_{b}$ with $\varphi$ for the five fuels. Three times of tests are carried out for each case, and the test data are fitted by first-order linear. The Markstein length in all the cases is positive in this study. It is seen that, with lean mixture of 0.8, PRF95 has the maximum Markstein length. While with rich mixture of 1.2, methane has the maximum Markstein length. The Markstein length of PRF95 decreases monotonically as the mixture becomes richer. The opposite trend occurred for methane. With the addition of methane, the changing tendency of dual fuel locates between the two base fuels. As the methane mixing ratio is up to 75\% (DF75), it changes the trend of evolution of dual fuel versus equivalence ratio.

The Markstein length indicates the influence of stretch rate on flame speed, which characterizes the 
diffusion-thermal instability. According to asymptotic theory [15,23], the Markstein length depends on the Lewis number of the fuel in lean equivalence ratio; in contrast it depends on the Lewis number of oxidizer in rich equivalence ratio. Therefore, the Markstein length will increase with the increase of equivalence ratio for light hydrocarbon-air mixtures. Meanwhile, it will decrease with the increase of equivalence ratio for heavy hydrocarbon-air mixtures $[13,17,24]$. These are consistent with the results of the present study.

\subsection{Laminar burning speed}

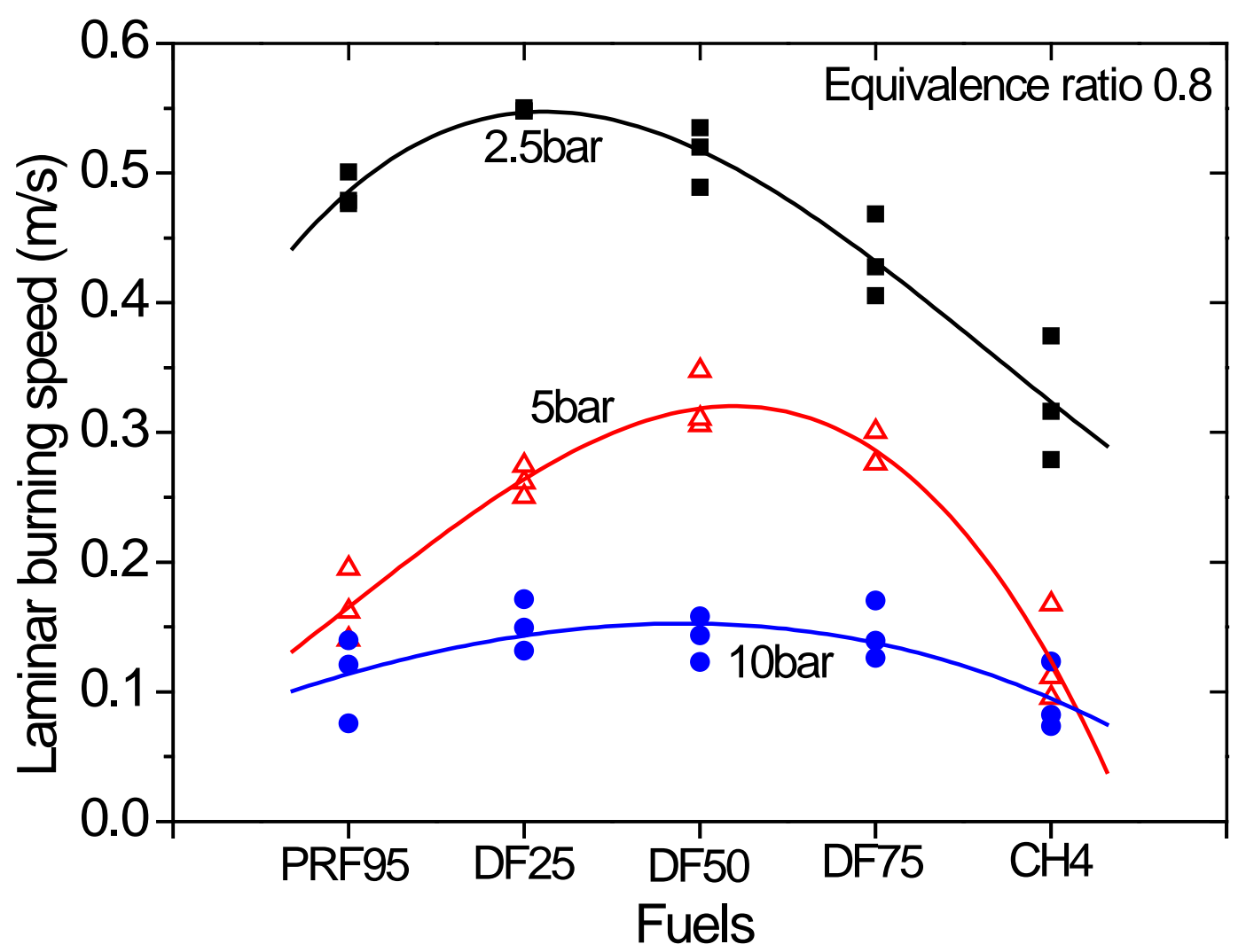

Fig. 10. Laminar burning speed versus different mixtures at equivalence ratio 0.8 .

Figure 10 shows the laminar burning speed versus different fuels under different initial pressures and with the equivalence ratio of 0.8 . At lean conditions, it has been found that the laminar burning speed of DFs is larger than those of pure PRF95 or methane over the whole range of mixing ratio investigated. Laminar burning speed decreases with the increase of the initial pressure for all the five fuels. As can be seen, the speeds of blended fuels are faster than that of the both base fuels under all the three conditions. The effect decays as pressure increases. At a pressure of 2.5 bar, the laminar flame of DF25 burned fastest than the other fuels. As the pressure increases, the peak value of laminar burning speed moves towards the mixture with high blending ratio of methane and DF50 has the fastest flame burning speed under initial pressure of 5 bar. When the initial pressure is up to $10 \mathrm{bar}$, the laminar burning speeds of the five fuels 
have minor difference, but the dual fuel still has a litter higher laminar burning speed than base fuels. In general, the present study indicates that the lean methane dual fuel is appropriate for lean combustion engine under low load and the stoichiometric combustion under middle load. This provides reference to the development of lean and homogeneous combustion engines.

\subsection{Flame instability}
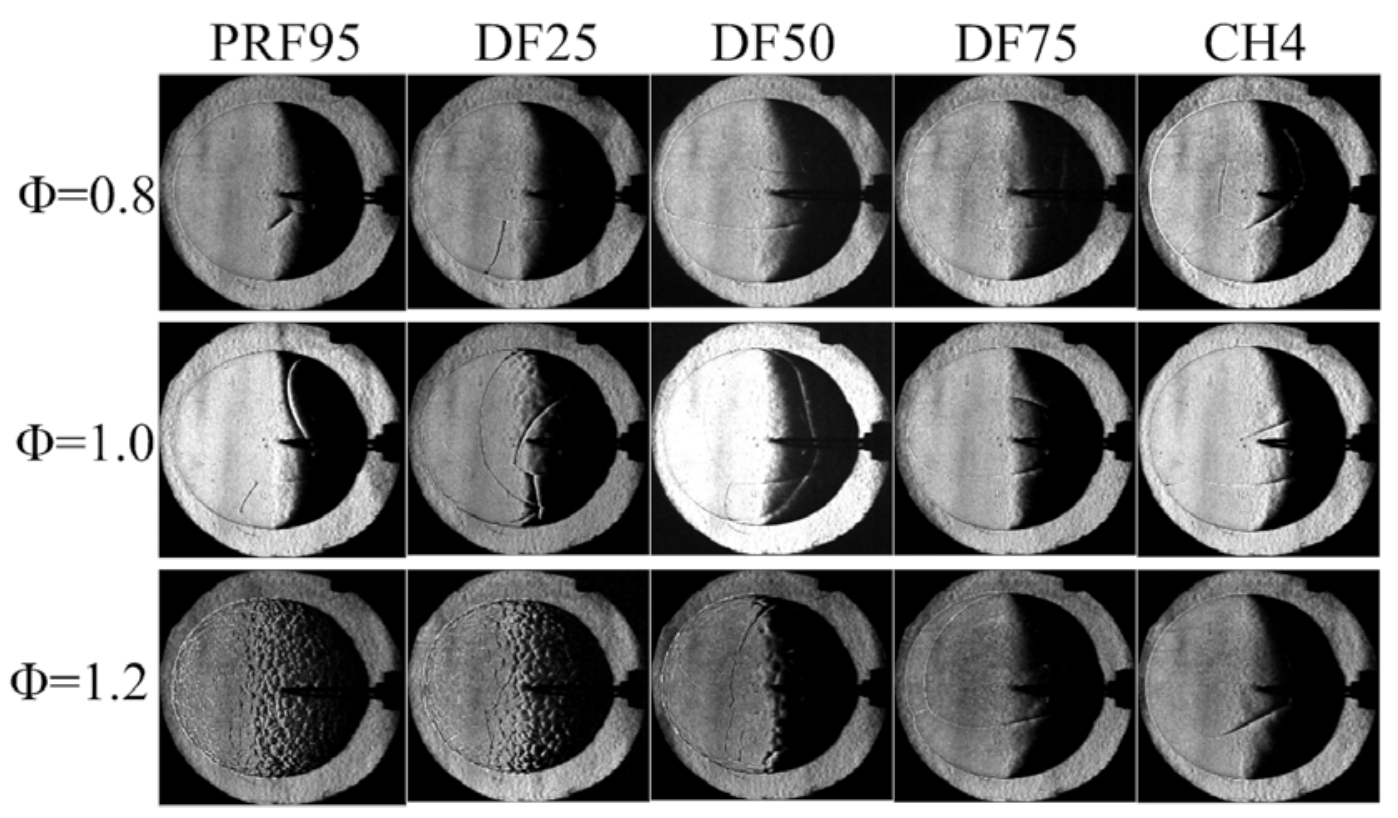

Fig. 11. Schlieren images of laminar flame at radius of $30 \mathrm{~mm}$, under initial pressure of 2.5 bar.

There are two main kinds of flame surface instabilities acting on the flame front under the conditions similar to those in the present work: the diffusion-thermal instability and the hydrodynamic instability [24-26]. Schlieren images of laminar flames are shown in Fig. 11 for methane, PRF95 and their blended fuels, at a flame radius of $30 \mathrm{~mm}$. For the images, three equivalence ratios of $0.8,1.0$ and 1.2 are employed. With the equivalence ratios of 1.0 and 0.8 , the flame propagations of the five fuels are stable (no cellular) with just one or two long “cracks" visible on the flame surface. As the radius shown, the flame of rich PRF95 mixture has a well developed irregular cellular structure across its surface at equivalence ratio of 1.2. With the addition of methane, the phenomenon of cell structure is gradually reduced at the equivalence ratio of 1.2. And DF50 is in critical radius where a cellular structure appears across the whole flame surface suddenly. The wrinkled flame surface is accompanied by an increase of flame speed, and the cells on the flame surface are observed to be subdivided into smaller cells as the flame continues to propagate outwardly. These are affected by hydrodynamic and diffusive-thermal instabilities, and the stretch rate has a more significant impact on the flame front. As shown in Fig. 4 and 
Fig. 11, the flame is initially stable because of the strong curvature-induced stretch stabilizing effect. As the flame propagates outwardly and the stretch rate decreases gradually, a critical state is reached at which cell development can no longer be suppressed and cellular appears almost instantaneously over the entire flame surface [24].

\section{Conclusions}

The effect of adding methane to PRF95 premixtures has been investigated experimentally. In each case, $25 \%, 50 \%$ and $75 \%$ by energy of methane are added. Experiments were conducted under 2.5 bar, 5 bar and 10 bar and the equivalence ratio varied with $0.8,1.0$ and 1.2. The main conclusions are summarized as following:

1. Adding methane to PRF95 increases the unstretched burning speed in lean region under low initial pressure (2.5 bar) while decreases it in rich region. Comparing the data of DF25 and the base fuels at $\varphi=0.8$, it can be seen that the flame speed of DF25 is $57 \%$ faster than that of methane and $22 \%$ faster than that of PRF95.

2. Laminar methane-PRF95 mixtures burns faster than those of pure methane and PRF95 at equivalence ratio of 0.8 over the whole range of initial pressures investigated, and this trend is more pronounced at low pressure. At initial pressure of 2.5 bar, with the decrease of methane mixing ratio, the development of laminar flame increases and the flame speed of DF25 is clearly the highest. As the pressure increases, the peak value of laminar burning speed moves towards the mixture with high blending ratio of methane.

3. The Markstein length of PRF95 decreases monotonically as the mixture became richer. The opposite trend occurs for methane. With the addition of methane, the changing tendency of dual fuel locates between the two base fuels.

4. With the addition of methane, the phenomenon of cell structure is gradually reduced with the same radius. The addition of methane to PRF95 results in later onset of laminar flame instability.

Although deep mechanism of this phenomenon has been tried to explain through detailed chemistry mechanism, the present mechanism also can’t obtain the trend like this paper. Therefore, more work about chemistry mechanism of dual fuel with methane and PRF needs to be done in future. However, the present work suggests that, low proportion of methane fuel blended gasoline can promote the development of laminar flame under the conditions of low pressure and with lean equivalence ratio. And the results also 
provide important theoretical references to lean burn SI engine with methane-gasoline dual fuel.

\section{Acknowledgement}

This work was supported by the National Natural Science Foundation of China (Grant No. 51476114) and the Research Fund for the Doctoral Program of Higher Education of China (Grant No. 20120032130004).

\section{References}

[1] Zhuang Y, Hong Guang. Effects of direct injection timing of ethanol fuel on engine knock and lean burn in a port injection gasoline engine. Fuel 2014;135:27-37.

[2] Korb B, Kawauchi S, Wachtmeister G. Influence of hydrogen addition on the operating range, emissions and efficiency in lean burn natural gas engines at high specific loads. Fuel 2016;164:410-8.

[3] Oh H, Bae C. Effects of the injection timing on spray and combustion characteristics in a spray-guided DISI engine under lean-stratified operation. Fuel 2013;107:225-35.

[4] Gou M, Detuncq B, Guernier C, et al. Performance of a single cylinder engine fuelled by a mixture of natural gas and gasoline. SAE Technical Paper 1990-02-01; 1990.

[5] Pipitone E, Beccari S. Performances improvement of a SI CNG bi-fuel engine by means of double-fuel injection. SAE Technical Paper 2009-24-0058; 2009.

[6] Delpech V, Obiols J, Soleri D, et al. Towards an innovative combination of natural gas and liquid fuel injection in spark ignition engines. SAE International Journal of Fuels and Lubricants 2010; 3(2):196-209.

[7] Li G, Liang J, Zhang Z, et al. Experimental investigation on laminar burning velocity and Markstein lengths of premixed methane-n-heptane-air mixtures. Energy Fuel 2015;29:4549-56.

[8] Serras-Pereira J, Aleiferis PG, Richardson D. An Analysis of the Combustion Behavior of Ethanol, Butanol, Iso-Octane, Gasoline, and Methane in a Direct-Injection Spark-Ignition Research Engine. Combust Sci Technol 2013;185:484-513.

[9] Baloo M, Dariani BM, Akhlaghi M, et al. Effect of iso-octane/methane blend on laminar burning velocity and flame instability. Fuel 2015;144:264-73.

[10] Jerzembeck S, Peters N, Pepiot-Desjardins P. et al. Laminar burning velocities at high pressure for primary reference fuels and gasoline: Experimental and numerical investigation. Combust Flame 2009;156:292-301.

[11] Mannaa O, Mansour MS, Roberts WL, et al. Laminar burning velocities at elevated pressures for gasoline and gasoline surrogates associated with RON. Combust Flame 2015;162:2311-21.

[12] Wei H, Gao D, Zhou L, et al. Experimental observations of turbulent flame propagation effected by flame acceleration in the end gas of closed combustion chamber. Fuel 2016;180:157-63.

[13] Bradley D, Hicks RA, Lawes M, et al. The measurement of laminar burning velocities and Markstein numbers for iso-octane-air and iso-octane-n-heptane-air mixtures at elevated temperatures and pressures in an explosion bomb. Combust Flame 1998;115:126-44. 
[14] Burke M P, Chen Z, Ju Y, et al. Effect of cylindrical confinement on the determination of laminar flame speeds using outwardly propagating flames. Combust Flame 2009;156:771-9.

[15] Law CK, Jomaas G, Bechtold J K. Cellular instabilities of expanding hydrogen/propane spherical flames at elevated pressures: theory and experiment. Proc Combust Inst 2005;30:159-67.

[16] Zhang Z, Huang Z, Wang X, et al. Measurements of laminar burning velocities and Markstein lengths for methanolair-nitrogen mixtures at elevated pressures and temperatures. Combust Flame 2009;155:358-68.

[17] Gu XJ, Haq M Z, Lawes M, et al. Laminar burning velocity and Markstein lengths of methane-air mixtures. Combust Flame 2000;121:41-58.

[18] Bechtold JK, Matalon M. The dependence of the Markstein length on stoichiometry. Combust Flame 2001;127:1906-13.

[19] Varea E, Modica V, Vandel A, et al. Measurement of laminar burning velocity and Markstein length relative to fresh gases using a new postprocessing procedure: Application to laminar spherical flames for methane, ethanol and isooctane/air mixtures. Combust Flame 2012;159:577-90.

[20] Luong MB, Luo Z, Lu T, et al. Direct numerical simulations of the ignition of lean primary reference fuel/air mixtures with temperature inhomogeneities. Combust Flame 2013;160:2038-47.

[21] Kelley AP, Liu W, Xin YX, et al. Laminar flame speeds, non-premixed stagnation ignition, and reduced mechanism in the oxidation of iso-octane. Proc Combust Inst 2011;33:501-8.

[22] Galmiche B, Halter F, Foucher F. Effects of high pressure, high temperature and dilution on laminar burning velocities and Markstein lengths of iso-octane/air mixtures. Combust Flame 2012;159:3286-99.

[23] Matalon M, Matkowsky BJ. Flames as gasdynamic discontinuities. J Fluid Mech 1982;124:239-59.

[24] Wu X, Huang Z, Wang X, et al. Laminar burning velocities and flame instabilities of 2, 5-dimethylfuran-air mixtures at elevated pressures. Combust Flame 2011;158:539-46.

[25] Law CK. Combustion Physics. Cambridge University Press, Cambridge, 2006.

[26] Rozenchan G, Zhu DL, Law CK, et al. Outward propagation, burning velocities, and chemical effects of methane flames up to 60 atm. Proc Combust Inst 2002;29:1461-470. 